\title{
Nos limites do dicionário: Zeigewörterbuch. Einfach auf alles zeigen. Stuttgart: Pons, 2014, 80 páginas.
}

Féliz Valentin Bugueño Miranda ${ }^{1}$

É perfeitamente possível afirmar que o denominador comum de qualquer dicionário é apresentar um conjunto de informações sobre a língua segundo um dado critério. Só em função desse consenso mínimo é que se pode considerar que o Zeigewörterbuch, doravante Zwtb (2014), constitui um dicionário e por nada mais. Zwtb (2014) não apresenta conjuntos de palavras sob nenhum critério de busca. Em consequiência, é para se perguntar se se pode aplicar o termo Wörterbuch [dicionário] à obra resenhada nessa oportunidade. A continuação da resenha abordará dois aspectos: O primeiro deles é tentar estabelecer por quais critérios Zwtb (2014) seria uma obra lexicográfica. O segundo, avaliá-la na sua potencial efetividade como obra de referência.

Zwtb (2014) não é o primeiro expoente de uma obra desenhada para a resolução de situações de comunicação que não oferece um conjunto léxico ordenado por qualquer critério identificável. Há um antecedente da editora Langenscheidt. No campo das especulações, poder-se-ia dizer que ambas as obras são a "continuação" dos Bildwörterbücher [dicionários pela imagem], uma classe de obras de referência amplamente cultivada pela lexicografia alemã. No entanto, ambas editoras arriscaram muito ao prescindir totalmente das palavras em uma obra de referência, mas mantendo o título de Wörterbuch [dicionário] para elas.

$\mathrm{Na}$ verdade, ao não haver substituição ostensiva, isto é, a permuta de uma "coisa" (uma gravura, na verdade) por uma designação, pareceria que se chega, inevitavelmente, aos limites daquilo que se poderia chamar de dicionário.

O único elo que relaciona a Zwtb (2014) com qualquer obra de referência léxica é a estrutura de acesso. Dito em outros termos, emprega-se o mesmo algoritmo de busca (ou princípio de ordenação): em clara analogia e continuidade com o dicionário pela imagem, Zwtb (2014) possui como princípio de ordenação um total de sete blocos temáticos, que correspondem, ao que parece, a sete situações comunicativas básicas de interação lingüística. Cada uma delas, por sua vez, aparece disposta pelos referentes dos signos linguísticos

\footnotetext{
${ }^{1}$ Universidade Federal do Rio Grande do Sul - UFRGS. Licenciado en Lengua y Literaturas Hispánicas, Universidad Católica de Valparaíso / CHILE. Doktor der Romanischen Philologie, Universität Heidelberg / ALEMANHA
} 
arquetípicos associados a cada situação comunicativa. Esses temas são: viajar [Reisen / Travel], pernoite [Übernachten / Stay the night], comer e beber [ Essen und trinken / Eat and drink], ir de compras [Shoppen / Go shopping], estar ativo [ Aktiv werden / Get ative], procurar ajuda [Hilfe finden / Get help], apontar para o mundo [Die Welt zeigen / Point to places]. Como é também comum na tradição dos dicionários pela imagem, essa ordenação temática é arbitrária e mais parece estar determinada, como já comentado, pelas possíveis situações comunicativas básicas com as que um viajante se poderia deparar.

Em relação ao primeiro tema, "viajar" [Reisen / Travel], as gravuras estão dispostas em função do que seria a progressão arquetípica de uma viagem, começando por gravuras referentes à chegada em um aeroporto. A continuação aparece uma segunda série de gravuras referentes a uma estação de trem, à qual seguem outras que têm relação com outras opções de viagem (de bicicleta, motocicleta, navio, etc.). O tema "viagem" termina com uma outra série de gravuras referentes a automóvel (Figura 1). É necessário reconhecer que o poder representacional de algumas das imagens é muito bom, como é o caso, por exemplo, quando, no aluguel de um carro, se deseja determinar as dimensões da viatura. Para isso, foram dispostas paralelamente duas gravuras, representando dois carros de dimensões claramente diferentes. Da mesma forma, quando o motorista requer água e/ou óleo, há duas gravuras dispostas também de forma paralela. Em uma delas, aparece a imagem de um regador em cujo interior se aprecia um líquido em movimento. Em contrapartida, na outra gravura, aparece, saindo do bico de um pequeno vaso de folha de forma cônica e gargalo estreito, uma única gota de líquido. Assim, a representação icônica de um líquido em movimento e de outro que sai vagarosamente leva à conclusão de que se trata de água, no primeiro caso, e de óleo no segundo. 


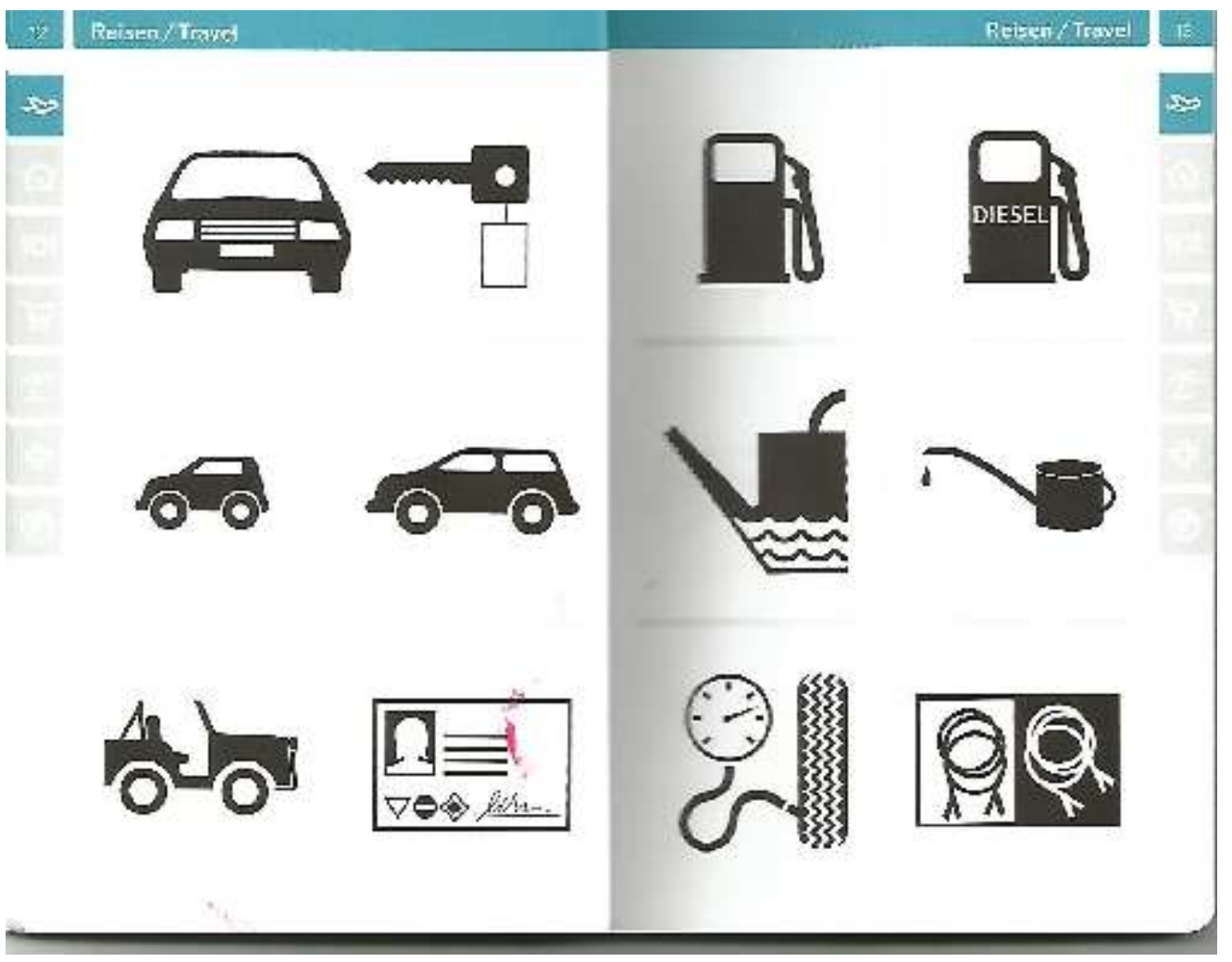

Figura 1: Alugando um carro

No tema referente ao "pernoite" [Übernachten / Stay at night], Zwtb (2014) troca as gravuras por fotografias. Não há razão aparente que permita compreender tal decisão. O único comentário que se pode fazer sobre esse particular é que as fotografias são de uma ótima qualidade.

Quase que inevitavelmente, nem todas as representações icônicas são suficientemente auto-explicativas. Assim, por exemplo, e ainda no tema "pernoite" [Übernachten / Stay at night], há duas gravuras representando notas e moedas (Figura 2). É custoso, porém, compreender que um símbolo que representa uma meia lua - que aparece uma única vez em uma primeira gravura - e multiplicado várias vezes na segunda, esteja assinalando a opção de um único pernoite frente à opção de vários pernoites em um hotel. 


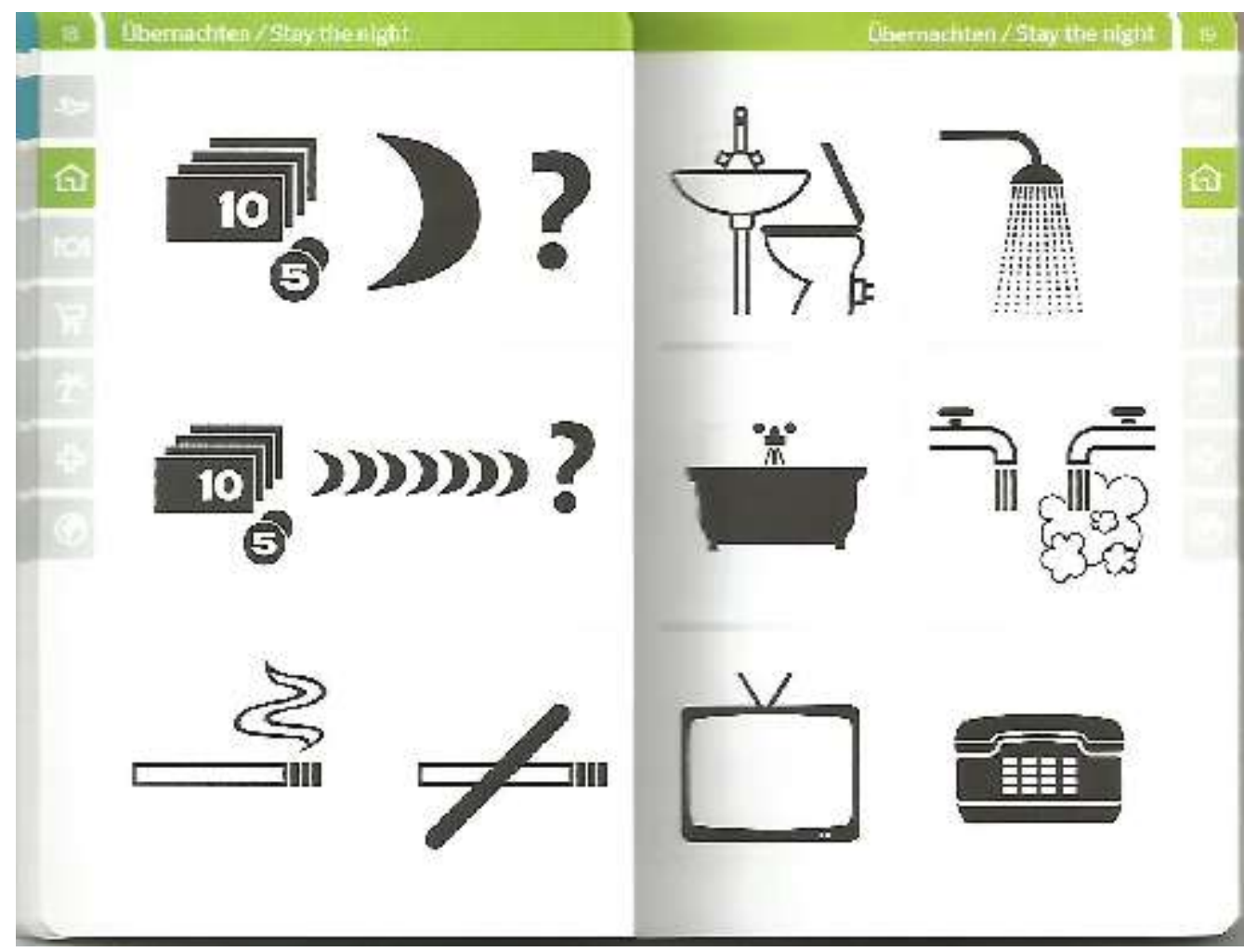

Figura 2: Pernoite em um hotel

Anteriormente, foi mencionado que as situações e as respectivas gravuras que as representam parecem ser produto de um conjunto de situações comunicativas que se julgaram prototípicas. Nesse sentido, e ainda no âmbito do tema "pernoite" [Übernachten / Stay the night], há uma série de gravuras que, de facto, representam todas as situações possíveis referentes a um pernoite em um hotel ou pousada, tais como a existência de um chuveiro, de água quente e/ou fria, acesso a telefone, fax, internet etc.

Conforme já comentado, Zwtb (2014), além de gravuras, emprega também fotografias. No tema "comer e beber" [Essen und trinken / Eat and drink], há, por exemplo, somente fotografias. A decisão parece plenamente justificada, já que nem sempre o emprego de desenhos permite oferecer uma representação perfeitamente icônica de certas entidades, como as frutas, em que as cores e as texturas são fundamentais para a correta identificação do objeto na realidade. Um outro caso é uma fotografia referente a tipos de bebidas alcoólicas (p.33). Só uma fotografia permite identificar e diferenciar o vinho do champanhe, por exemplo.

Dentre as sete situações Zwtb (2004), a perfeita iconicidade exposta em "procurar ajuda" " [Hilfe finden / Get help] torna este tema um dos que está melhor representado. O tema começa com três gravuras referentes aos agentes públicos primários que todo viajante procuraria em caso de emergência: a polícia, os bombeiros e a sua própria representação 
consular. Em seguida, há seis gravuras referentes a situações passíveis de acontecerem: perguntar por uma cabine telefônica, informar um roubo, assalto ou incêndio e pedir um extintor ou uma mangueira. Naturalmente, há um conjunto de desenhos restrito a uma emergência médica (Figura 3). Nesse item, destaca-se um grupo de seis gravuras de altíssimo poder icônico, e que se propõem a informar que a pessoa é alérgica às plantas, sensível à insolação, se padece de vômitos, diarréia ou constipação, ou se sofreu uma queimadura. Seguramente, tais figuras correspondem às situações melhor representadas iconicamente em Zwtb (2014), tanto pelo seu caráter representacional, conforme já dito, como também pela pertinência das situações extralinguísticas que almejam representar.

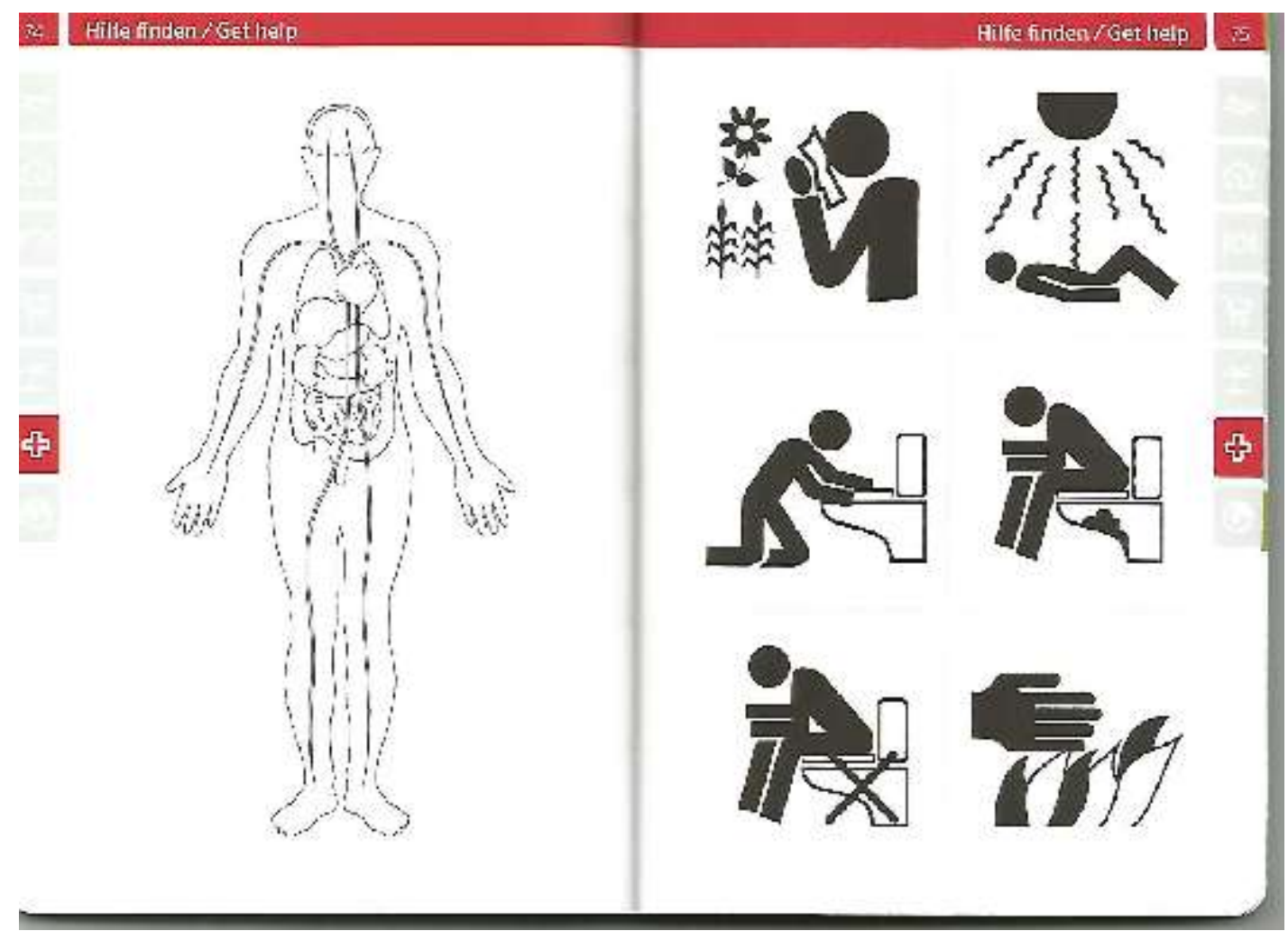

Figura 3: Procurando ajuda médica

Em síntese, Zwtb (2014) precisa ser avaliado à luz de uma dupla perspectiva. Por um lado, do ponto de vista da teoria metalexicográfica, vista a sua auto-intitulação de Wörterbuch [dicionário]. Por outro lado, do ponto de vista da tarefa que almeja cumprir, que não é outra que a de permitir o entendimento entre (um) interlocutor(es) em determinadas situações, sem a mediação da linguagem.

No que diz respeito à sua condição de "dicionário", é questionável, sem dúvida alguma, se Zwtb (2014) pode ser classificado como uma obra lexicográfica. Nesse sentido, tanto a editora Pons como qualquer outra editora, precisaria procurar um título mais 
adequado. Sem dúvida alguma, o rótulo Wörterbuch [dicionário] é altamente apelativo em um país como a Alemanha, que faz do dicionário um objeto primordial e de culto. No entanto, Zwtb (2014) não é - insistimos - uma obra lexicográfica. Fica para a tarefa acadêmica (e editorial também, aliás!) refletir sobre a constituição, desenho e aprimoramento dessas obras.

Do ponto de vista da tarefa que Zwtb (2014) almeja cumprir, que é permitir a interação comunicativa básica quando se desconhece completamente uma língua estrangeira, ela se cumpre de forma satisfatória. Indubitavelmente, sempre haverá algum aspecto pontual a melhorar, mas, como um todo, até o próprio autor da resenha empregaria Zwtb (2014) em um país cuja língua não dominasse.

Trata-se de uma obra recomendável. Empfehlenswert! 